\title{
Accessing out-of-hours care following implementation of the GMS contract: an observational study
}

\author{
Suzanne H Richards, Rachel Winder, David Seamark, Clare Seamark, Paul Ewings, Angela Barwick, \\ James Gilbert, Sarah Avery, Sarah Human and John L Campbell
}

\author{
ABSTRACT \\ Background \\ There is widespread concern that the quality of out-of- \\ hours primary care for patients with complex needs may \\ be at risk now that the new general medical services \\ contract (GMS) has been implemented. \\ Aim \\ To explore changes in the use of out-of-hours services \\ around the time of implementation of the new contract for \\ patients with complex needs, using patients with cancer \\ as an example. \\ Design of study \\ Longitudinal observational study.

\section{Setting} \\ Out-of-hours primary care provider covering Devon (adult \\ population 900000 ), UK. \\ Method \\ Two, 1-year periods corresponding to pre- (April 2003 to \\ March 2004) and post-contract implementation (October \\ 2004 to September 2005) were sampled. Call rates per \\ 1000 of the adult population (age $\geq 16$ years) were \\ calculated for all calls (any cause) and cancer-related \\ calls. Anonymised outcome and process measures data \\ were extracted. \\ Results \\ Although overall call rates per 1000 population had \\ increased by $26 \%$ (185 pre-contract to 233 post- \\ contract), the proportion of cancer-related calls remained \\ relatively constant $(2.08 \%$ versus $1.96 \%)$. Around half \\ (56\%) of these callers had advanced cancer needs \\ (including palliative care). By post-contract, the time \\ taken to triage had significantly increased $(P<0.001)$. \\ Although the proportions admitted to hospital or receiving \\ a home visit remained constant, calls where a special \\ message was sent by the out-of-hours clinician to the \\ in-hours team had decreased $(P<0.001)$.

\section{Conclusion} \\ The demand for out-of-hours care for patients with cancer \\ did not alter disproportionately after implementation of the \\ contract. While potential quality indicators (for example, \\ hospital admissions, home visiting rates) remained \\ constant, potentially adverse changes to triage time and \\ communication between out-of-hours and in-hours \\ clinicians were observed. Quality standards and provider \\ databases require further refinement to capture elements \\ of care relevant to patients with complex needs.

\section{Keywords} \\ cancer care; cohort study; healthcare delivery; out-of- \\ hours medical care; primary health care.
}

\section{INTRODUCTION}

In the UK, 'out-of-hours' is defined as care provided between the hours of $18: 30$ and $8: 00$ or at the weekends and bank holidays. ${ }^{1}$ The majority of outof-hours care (around 69\%) is outside the normal working hours of primary care services. ${ }^{2}$ Approximately $13 \%$ of the population use out-ofhours services each year, of whom around one-third contact primary care providers. ${ }^{3}$ Many users are from the more vulnerable members of society, such as children under 5 years of age, older people, or individuals with complex healthcare needs. ${ }^{4,5}$

The delivery of out-of-hours primary medical care has altered substantially over the last 20 years, ${ }^{3,6}$ and particularly in response to the Carson review, which delivered a critical verdict on issues of quality, safety, and effectiveness. ${ }^{7}$ Subsequent modernisation activities have focused on improving

$S$ Richards, BSc, $P h D$, senior lecturer in primary care; $\boldsymbol{R}$ Winder; associate research fellow; D Seamark, PhD, FRCGP; GP, honorary senior clinical research fellow;

JL Campbell, professor of general practice and primary care; A Barwick, MBChB, Macmillan GP facilitator, Primary Care Research Group, Peninsula Medical School, Plymouth. C Seamark, MD, FRCGP, GP, Honiton Surgery, Honiton, Devon. $P$ Ewings, BSc, PhD, director of Somerset RDSU, and medical statistician, Taunton and Somerset Hospital, Taunton. J Gilbert, FRCP, medical director of Hospiscare and palliative care consultant; S Human, MRCGP, specialist registrar, Exeter Hospiscare, The Exeter and District Hospice; S Avery, clinical governance manager, Devon Doctors, Exeter.

Address for correspondence

Dr Suzanne Richards, Peninsula Medical School — Primary Care, Institute of Health Services Research, Smeall Building, St Luke's Campus, Magdalen Road, Exeter, EX1 2LU.

Email: suzanne.richards@pms.ac.uk

Submitted: 24 July 2007; Editor's response: 6 November 2007; final acceptance: 5 February 2008.

(c)British Journal of General Practice 2008; 58: 331-338.

DOI: 10.3399/bjgp08X280191 


\section{How this fits in}

There is widespread concern that the implementation of the new general medical services (GMS) contract might be associated with reduced quality of care for patients with complex care needs seeking out-of-hours primary care. This longitudinal observational study explored the impact of the new contract for patients with cancer on key process and outcome measures from out-ofhours consultations. The overall demand (any cause) for out-of-hours care increased by around $26 \%$ following implementation of the contract. While the proportion of cancer-related calls remained constant, and potential quality indicators, such as hospital admissions or home visiting, remained unchanged, potentially detrimental changes in triage time and communication between outof-hours and in-hours clinicians were observed. Around half of all cancer-related calls were by people with advanced cancer (including palliative care) needs. Current national quality standards and provider information systems require further refinement to support the routine monitoring of elements of care that are of particular relevance to patients with complex needs.

patient access to urgent care, and the implementation of quality standards to monitor performance. $^{8}$ From the general practice perspective, the tensions around delivering out-ofhours care through the cooperative model culminated in the implementation of the new general medical services (GMS) contract. ${ }^{1}$ By October 2004, GPs were able to opt out of the responsibility for commissioning and providing outof-hours care, with this responsibility passing to the primary care trusts (PCTs); unsurprisingly, the vast majority of GPs opted out. ${ }^{3}$

In many areas, PCTs commissioned the existing cooperatives. The extent to which services altered as a result of the contract is debatable, although in some areas PCTs have commissioned private ('for profit') providers. The geographical area covered by many cooperative providers has also increased due to economies of scale around implementing clinical governance, and quality standards reporting.

A recent National Audit Office report concluded that not all providers are meeting the national quality requirements, in particular regarding speed of response. ${ }^{3}$ The severing of the link between in-hours general practice-based care and out-of-hours services has also crystallised concerns about how patients with complex needs can be appropriately managed. ${ }^{2,9,10}$ Patients with complex needs, particularly those with urgent cancer and/or palliative care needs, may be especially vulnerable if the on-call changes impact on the continuity of care between general practice and the out-of-hours team. .,, $11^{11}$

This study explores whether the implementation of the new contract is associated with changes in access to out-of-hours primary care services for patients with complex needs. Using patients with cancer as an example, it reports the methodology for identifying cancer-related calls and for the subgroup of callers with advanced cancer-related needs. It then explores changes in the pattern of out-of-hours process (for example, waiting time until triage), and outcome measures (for example, hospital admissions rates $)^{2}$ which may indicate changes in the quality of care.

\section{METHOD}

\section{Design}

A longitudinal, observational study was undertaken, documenting changes in the use of out-of-hours primary care services in Devon for adult patients with cancer, before and after the implementation of the new GMS contract on 1 April 2004.

\section{Setting}

Prior to the implementation of the new contract, most GPs in Devon (approximately 174 practices) were working for one of eight cooperatives, with only a small number organising care through deputising services. These cooperatives had already merged their administrative procedures and databases into a single, not-for-profit organisation (Devon Doctors) in preparation for when the responsibility for commissioning care passed to the eight PCTs after implementation of the new contract. Clinical staffing remained relatively stable, with a high proportion of existing GPs continuing to commit to providing outof-hours care through the emergent organisation.

Devon has a mixed patient population, including urban and rural communities, with one large innercity area, and varying levels of deprivation, but low levels of ethnic minority representation. ${ }^{12}$ A summary of the patient care pathway is provided in Figure 1.

\section{Sampling}

Ascertaining cancer-related calls. All calls to the Devon Doctors are recorded on an Adastra database. Records include the patient's contact details, a summary of their clinical needs (text fields for symptoms, diagnosis, and notes), and the management provided. Electronic search terms were used to identify potential cancer-related calls (Box 1).

The accuracy of search terms was established in a sample of 300 calls (any cause), which were manually inspected by two independent blinded assessors who judged patients' cancer status (yes/no/uncertain). The manually-identified cancer calls were compared with those identified electronically. Sensitivity, specificity, ${ }^{13}$ and associated 95\% confidence intervals (Cls) were calculated.

Two sampling frames were used: a pre-contract period between April 2003 and March 2004, and a post-contract period between October 2004 and September 2005, avoiding the 6-month transition 


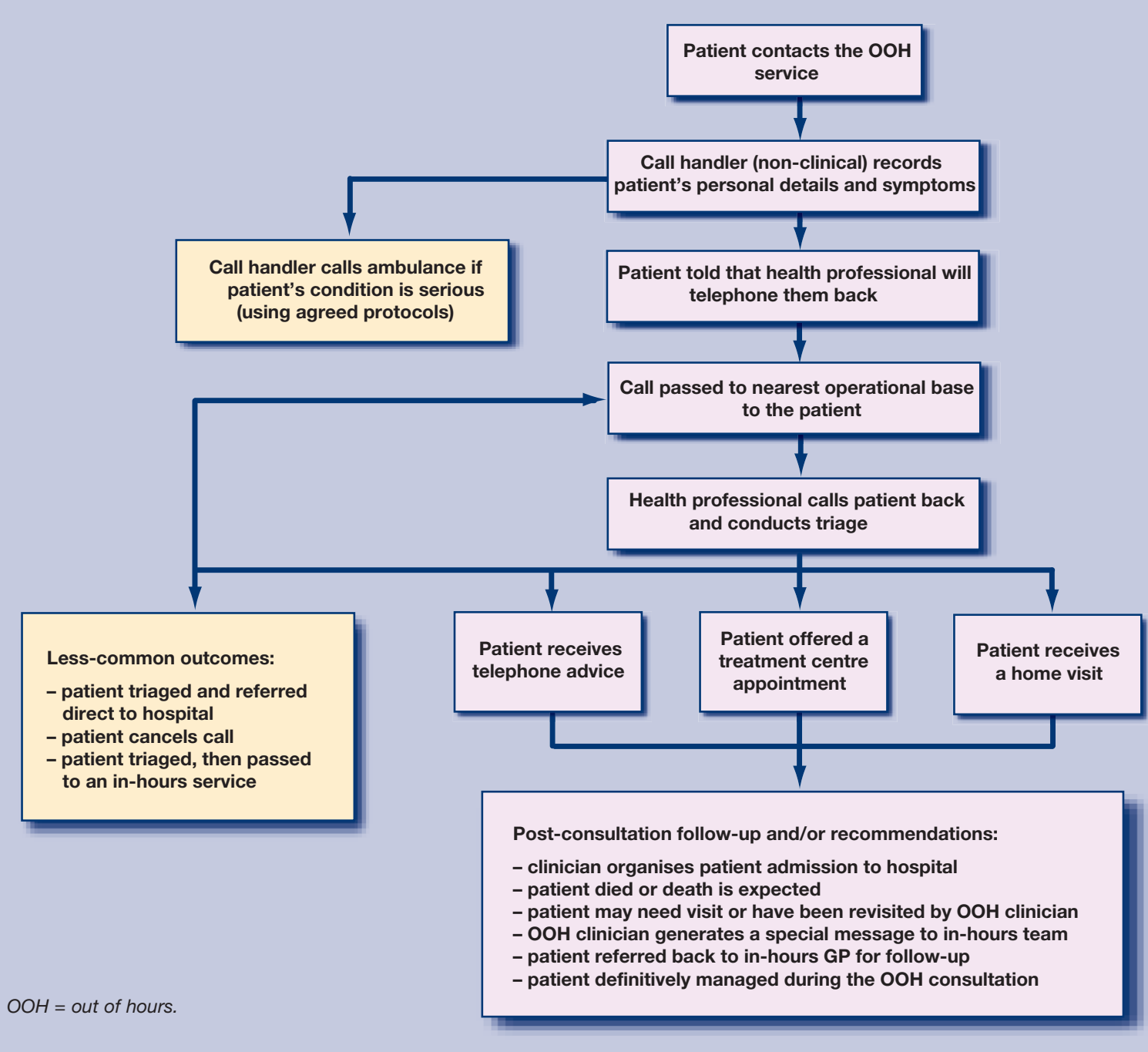

period. The electronic records documenting requests for medical assistance made by adult patients (aged 16 years or over) during the two time periods were electronically searched to identify callers with potential cancer diagnoses, irrespective of whether or not their use of the service was related to their cancer diagnosis. The resultant calls were manually inspected by two assessors to ascertain cancer status. Cases with uncertain status, or those where the two coders disagreed, were recoded by a third medically qualified assessor. Once cancer status had been established, calls were fully anonymised and all clinical descriptive data removed before process and outcome data were extracted.

\section{Ascertaining calls with advanced cancer}

Using the World Health Organization definition of palliative care, ${ }^{14}$ the medically qualified researchers developed a list of basic definitions (Box 1) to identify callers with advanced cancer-related (including palliative care) needs. Two clinicians independently coded a $10 \%$ subset of established cancer calls into one of three categories: advanced cancer, not advanced, uncertain. Where disagreements arose, a third assessor adjudicated.

\section{Process and outcome measures}

Anonymised data describing the number of calls (any cause) and for the subset of callers with a cancer diagnosis were collated for each time period, and a call rate per 1000 of the adult population ( $\geq 16$ years old) calculated (Table 1). For cancerrelated calls, basic descriptive information was extracted on patient age, sex, and call outcomes including the 'six categories of management' option and six categories of post-consultation follow-up care and/or advice offered (categories described in Table 2). Process measures on the key timing points were extracted for:

- call logged by a call handler;

- clinical triage initiated; and

- care episode concluded (latter two recorded by health professional).
Figure 1. Patient pathway through the out-of-hours primary care service. The blue pathway represents the usual care pathway, while the yellow pathway represents less-common options that might be accessed. 


\section{Box 1. Identifying and categorising cancer status and} advanced cancer status including palliative care needs.

Electronic search terms: cancer status (yes/no/uncertain)

$\begin{array}{lllll}\text { [space]ca[space] } & \mathrm{Ca} \text { [space] } & \text { cancer } & \text { carcin growth } \\ \text { leuk lymph } & \text { malig } & \text { metast } & \text { mets } \\ \text { neop sarc } & \text { secondar } & \text { tumour } & \text { mesothel }\end{array}$

Criteria for defining cases of advanced cancer including palliative care needs (yes/no/uncertain).

The call record (previously identified as cancer-related) shows evidence of at least one of the following criteria:

evidence of metastatic disease;

evidence of locally advanced disease;

currently taking strong opioid treatment;

patient currently known to specialist palliative care service; or

evidence that death is expected within weeks.

In addition, each call must show that:

the caller's problem is plausibly related to the cancer diagnosis.

The timing points were used to calculate the time taken until triage (clinical triage initiated minus call logged by a call handler), and the time taken to resolve the care episode (care episode concluded minus clinical triage initiated).

\section{Data analysis}

All statistical analyses were undertaken using STATA (version 8.2).

Primary exploratory analyses. The primary analyses were exploratory, aiming to identify changes in service usage for patients with a cancer diagnosis before and after implementation of the contract. Differences between pre- and post-contract periods for call rates (all cause) and cancer-related calls per

\section{Table 1. Summary of frequency and call rates during pre-contract and post-contract periods for all calls and cancer-related calls.}

\begin{tabular}{lcc} 
Population & Pre-contract & Post-contract \\
\hline Adult population ( $\geq 16$ years old) of Devon & $891800^{\mathrm{a}}$ & $906100^{\mathrm{a}}$ \\
\hline Type of call & & \\
Number of calls (all cause) & $165064^{\mathrm{b}}$ & $210766^{\mathrm{b}}$ \\
Call rate (all cause) per 1000 population & 185 & 233 \\
\hline Cancer-related calls & & \\
Number of cancer-related calls & 3433 & 4141 \\
Proportion of all calls that were cancer-related $(\%)$ & 2.08 & 1.96 \\
Call rate (cancer) per 1000 population & 3.85 & 4.57 \\
\hline
\end{tabular}

${ }^{\text {a}}$ Figures from the Office of National Statistics mid-year estimates for Devon. ${ }^{\mathrm{b}} \mathrm{Call}$ frequencies reported are for core medical services, and exclude requests for deputising district nursing services.
1000 of the population, response times, and outcomes of all contacts were explored using statistical tests (5\% significance level) and, where appropriate, by presenting the absolute risk difference, and relative risk and associated 95\% Cls. ${ }^{15}$ Appropriate parametric (t-tests) or nonparametric (Mann-Whitney $U$ test or Kruskal-Wallis test) statistics were selected, depending on the distribution of data. ${ }^{16}$ The proportion of cancerrelated calls made by patients with advanced cancer was also estimated.

Sample size considerations. Preliminary data for a 1month period of August 2004 identified 217 requests for medical care from patients with cancer, equivalent to $1.3 \%$ of all calls $(215 / 17007)$. As a proportion of all calls made, to detect a $10 \%$ change in the proportion of cancer-related calls (with $80 \%$ power) requires assessment of a minimum of 127000 calls (any cause).

\section{RESULTS}

\section{Identifying cancer-related calls}

The electronic terms identified five cancer-related cases from 300 calls (any cause), and six cases were identified by manual review (sensitivity $=83.3 \%$, $95 \% \mathrm{Cl}=43.6$ to 97.0 ; specificity $=96.9 \%, 95 \% \mathrm{Cl}$ $=94.3$ to 98.4 ). Five of six cancer-related calls were identified by both electronic and manual methods; inspection of the case missed by electronic searching led to the inclusion of a new search term (Ca[space]). Manual inspection also identified a group of calls from patients who had died and for whom death was expected, but where the cause was not recorded $(4 / 300 ; 1.3 \%)$.

Of 370220 calls to the out-of-hours service for the two sample periods, 10977 potentially cancerrelated calls were identified by the electronic search terms, of which 963 were excluded (862 calls from patient aged < 16 years; 27 calls logged in error; 41 calls for daytime message-handling services). Of the remaining 10034 calls that were manually inspected, 8085 (80.6\%) were cancer related, 1782 (17.8\%) were not cancer related, and only 167 (1.7\%) remained uncertain. The proportion of records where the two assessors were in agreement was high (9597/10 034; 95.6\%).

Of the 8085 cancer-related calls, the majority $(7574$ calls; pre-contract $=3433$, post-contract $=4141$ ) were requests for core medical care services provided by Devon Doctors. A small number of calls ( $n=511$ ) were for a messaging-handling service for district nursing teams. The observed increase in the number of cancer-related calls to district nursing services between pre- and post-contract periods (from 116 to 427 calls) is a consequence of an 
Table 2. Summary of management and follow-up options received for cancer-related calls at baseline and follow-up.

\begin{tabular}{|c|c|c|c|c|c|c|}
\hline & \multicolumn{2}{|c|}{ Time period } & \multirow{2}{*}{$\begin{array}{l}\text { Absolute risk } \\
\text { difference } \\
\text { (post-pre), \% }\end{array}$} & \multirow[b]{2}{*}{$\begin{array}{l}\text { Relative risk } \\
(95 \% \mathrm{Cl})\end{array}$} & \multirow[b]{2}{*}{$\chi^{2}$} & \multirow[b]{2}{*}{$P$-value } \\
\hline & $\begin{array}{c}\text { Pre-contract, } \\
n(\%)\end{array}$ & $\begin{array}{c}\text { Post-contract, } \\
n(\%)\end{array}$ & & & & \\
\hline \multicolumn{7}{|l|}{ Management option received } \\
\hline Patient receives telephone advice & $1247(36.3)$ & 1757 (42.4) & 6.1 & $1.17(1.10$ to 1.24$)$ & 29.2 & $<0.001$ \\
\hline Patient offered a treatment centre appointment & $304(8.9)$ & $454(11.0)$ & 2.1 & $1.24(1.08$ to 1.42$)$ & 9.3 & 0.002 \\
\hline Patient receives a home visit & $1431(41.7)$ & $1659(40.1)$ & -1.6 & $0.96(0.91$ to 1.01$)$ & 2.0 & 0.150 \\
\hline Patient referred direct to hospital ${ }^{a}$ & $68(2.0)$ & $91(2.2)$ & 0.2 & $1.11(0.81$ to 1.51$)$ & 0.4 & 0.510 \\
\hline Patient cancels call & $12(0.3)$ & $46(1.1)$ & 0.8 & 3.18 (1.69 to 5.99$)$ & 14.3 & $<0.001$ \\
\hline Patient triaged, then passed to an in-hours service ${ }^{b}$ & $371(10.8)$ & $134(3.2)$ & -7.6 & $0.30(0.25$ to 0.36$)$ & 172.9 & $<0.001$ \\
\hline \multicolumn{7}{|l|}{ Post-consultation follow-up and/or recommendations } \\
\hline Clinician organises patient admission to hospital ${ }^{c}$ & $385(11.2)$ & $499(12.1)$ & 0.8 & 1.07 (0.95 to 1.22$)$ & 1.3 & 0.260 \\
\hline Patient died or death is expected & $123(3.6)$ & $187(4.5)$ & 0.9 & 1.26 (1.01 to 1.58$)$ & 4.2 & 0.040 \\
\hline Patient may need/or have been re-visited by $\mathrm{OOH}$ clinician & $12(0.3)$ & $77(1.9)$ & 1.5 & $5.32(2.90$ to 9.76$)$ & 36.9 & $<0.001$ \\
\hline $\mathrm{OOH}$ clinician issues a special message to in-hours team & $212(6.2)$ & $126(3.0)$ & -3.1 & $0.49(0.40$ to 0.61$)$ & 43.2 & $<0.001$ \\
\hline Patient referred back to in-hours GP for follow-up & $73(2.1)$ & $536(12.9)$ & 10.8 & 6.09 (4.79 to 7.74$)$ & 297.0 & $<0.001$ \\
\hline Patient definitively managed during the $\mathrm{OOH}$ consultation & 2628 (76.6) & $2716(65.6)$ & -11.0 & 0.86 (0.83 to 0.88$)$ & 108.6 & $<0.001$ \\
\hline
\end{tabular}

$\mathrm{OOH}=$ out-of-hours. 'Given the small numbers receiving the management options of 'call handler calls ambulance for patient', or 'patient triaged and referred direct to hospital', for analysis purposes these categories have been collapsed into 'patient referred direct to hospital'. ' $T$ This category is used when the out-ofhours clinician determines that the caller's needs are more appropriately met through consultation with another in-hours service (for example, community nursing team) but not their GP. 'This category was used in combination with the management outcome category of 'patient referred direct to hospital' for $42 / 385$ calls (10.9\%) during the pre-contract period and 54/499 calls (10.8\%) post-contract. For all other calls this follow-up option was used in combination with the management options of home visit (pre-contract 229/385, 59.5\% versus post-contract $247 / 499,49.5 \%)$, treatment centre $(45 / 385,11.7 \%$ versus $86 / 499,17.2 \%)$, or telephone advice (69/385, $17.9 \%$ versus $109 / 499,21.8 \%)$.

expansion of the deputising service. The primary analysis was therefore restricted to core medical services to ensure that the population coverage remained relatively constant.

\section{Identifying patients with advanced cancer}

Agreement between two assessors was lower $(515 / 730 ; 70.6 \%)$ than that observed for cancerstatus ascertainment, and 109/730 (14.9\%) calls could not be definitively coded. A conservative estimate of $56 \%(346 / 621)$ of calls (for which a definitive judgement could be made) were from patients with advanced cancer needs.

\section{Analysis of call rates}

The frequency of calls to the service for any cause, and for the subset of cancer-related calls for each time period is given in Table 1. Between pre- and post-contract periods, calls (any cause) per 1000 population increased by $26 \%$. Cancer-related calls also increased by $21 \%$, so that the overall proportion of calls that related to cancer demonstrated a small decrease.

The 7574 cancer-related calls were made by a total of 4905 individuals. These individuals were broadly similar between pre- and post-contract periods in respect of age (mean $=69.7$ years, $95 \%$ $\mathrm{Cl}=69.1$ to 70.3 , versus 69.9 years, $95 \% \mathrm{Cl}=69.4$ to $70.5 ; P=0.57)$, and sex $(48.5 \%$ female in both periods; $P=0.98)$.

\section{Analysis of call outcomes}

The overall distribution of callers receiving management options and post-consultation followup and/or recommendations differed between preand post-contract periods (Table 2; $P<0.001$ for each outcome).

The main changes in the proportions of callers receiving each of the management options were increases both in callers receiving telephone advice and in those attending a treatment centre, offsetting the reduction in callers passed to an 'in-hours'

Table 3. Summary of the time taken from logging the call until the start of triage, and from the start of triage until the call is resolved by the health professional during pre-contract and post-contract periods.

\begin{tabular}{lccc} 
& \multicolumn{2}{c}{ Year } & Mann-Whitney \\
\cline { 2 - 3 } Time taken to start of triage & $\begin{array}{c}\text { Pre-contract } \\
(n=3100)\end{array}$ & $\begin{array}{c}\text { Post-contract } \\
(n=3847)\end{array}$ & $\begin{array}{c}\text { Z score } \\
(P \text {-value })\end{array}$ \\
\hline Median minutes (IQR) & $\begin{array}{c}33 \\
(13 \text { to } 62)\end{array}$ & $\begin{array}{c}41 \\
(17 \text { to } 79)\end{array}$ & $\begin{array}{c}-8.95 \\
(<0.001)\end{array}$ \\
\hline Mean minutes (95\% Cl) & $\begin{array}{c}46.1 \\
(44.3 \text { to } 47.9)\end{array}$ & $\begin{array}{c}61.7 \\
(59.1 \text { to } 64.2)\end{array}$ & \\
\hline Time taken from triage to call resolution & $(n=3098)$ & $(n=3837)$ & \\
\hline Median minutes (IQR) & 10 & 9 & -0.853 \\
\hline Mean minutes (95\% Cl) & $(4$ to 16) & $(4$ to 17) & $(0.39)$ \\
\hline
\end{tabular}

$I Q R=$ interquartile range. 
service for clinical care. While patient cancellations trebled, the numbers of callers involved were small. In terms of the post-consultation follow-up and/or recommendations, the proportions of callers who were hospitalised, or who were identified as dying, or where death was expected, remained relatively constant.

More callers were identified as potentially needing revisiting or having been revisited (the numbers were small), or were advised to seek further assistance from their in-hours GP. These changes were balanced against decreases in the proportions of calls categorised as definitively managed (although this remained the outcome for about two-thirds of calls) during the out-of-hours consultation, or where a special message had been relayed from the outof-hours clinician direct to the in-hours team.

\section{Analysis of process measures}

The distribution of the frequency data for process measures was highly positively skewed (Table 3 ). The proportions of missing data varied from 333/3433 $(9.7 \%)$ of records at baseline to $294 / 4141(7.1 \%)$ at follow-up with no recorded start time of the triage. The time at which the call episode was resolved was also missing for $355 / 3433(9.8 \%)$ records at baseline and $304 / 4141$ (7.3\%) at follow-up. More problematic, however, was the substantial proportion of calls with the same time recorded by the health professional at 'start' triage and 'resolution of contact' ('0 minutes' to resolve call) during baseline $(545 / 3433,17.6 \%)$ and follow-up (601/4141, 15.7\%).

At follow-up, the time interval between the initial call being logged and the start of triage was significantly longer $(P<0.001)$ than that observed at baseline (Table 3). There was, however, no difference in the time taken to resolve the care episode $(P=$ 0.39). Sensitivity analyses, where various assumptions were made about the impact of implausible consultation length data (data not presented), did not alter this observation.

\section{DISCUSSION}

\section{Summary of main findings and comparison with existing literature}

This study estimated that around $2 \%$ of calls to the out-of-hours service are by patients with cancer, of which around a half (56\%) have advanced cancer and/or palliative care needs. This figure is conservative, as $15 \%$ of cancer calls could not be classified due to a lack of information on cancer staging. Electronic searches will also have missed around $1.3 \%$ of all calls in cases where the patients had died and where death was expected, but where the cause of death was not recorded. National (English) data suggest that around one-quarter of these calls might be attributable to cancer. ${ }^{17}$ The figures in the present study are broadly comparable to those of a previous study of out-of-hours cooperatives, which identified that $2.1 \%$ of all calls were for palliative care patients (any cause). ${ }^{18}$

The out-of-hours service experienced a substantial increase in call rates after the implementation of the new contract, although the proportion of cancer-related calls remained constant. The increased demand is probably attributable to the standardisation of the working hours around the time of handover between in-hours and out-of-hours services, combined with the loss of Saturday morning clinics provided by general practices.

Contrary to widespread concerns expressed among the primary care community, ${ }^{2,9,10}$ while the introduction of the contract may be associated with increased demand for out-of-hours care, there is no conclusive evidence that the demand from patients with complex needs altered disproportionately; rather it is likely that these patients were simply seeking help from the primary care service available to them at the time at which their needs arose (for example, on a Saturday morning).

Statistically significant changes in the proportions of callers receiving different management and follow-up options were observed, although care must be taken when interpreting the clinical significance of these changes, given the large sample available for analysis. Stability of the proportions of callers who received a home visit or who were admitted to hospital suggests that, although the service has experienced increased demand (all causes), this did not result in negative sequelae such as spiralling hospital admission rates or greater difficulties in accessing a home visit for callers with cancer.

Changes in some outcomes, such as the decline in out-of-hours clinicians who definitively resolved the care episode, could be consistent with reduced quality of care. However, an alternative explanation is more credible for some of these changes, namely that clinicians have simply altered their use of certain categories across time (for example, 'refer to in-hours GP for follow-up' is increasingly used now in preference to 'patient definitively managed by out-of-hours service'). The latter explanation cannot, however, account fully for the reduction (absolute decrease of $3.1 \%$ ) in the proportion of calls where the out-of-hours clinician issued a special message direct to the in-hours team to alert them to important clinical information. In the absence of reliable data on case-mix severity, it is impossible to interpret these changes more fully. Notwithstanding this, the observed decrease in inter-agency communication is likely to be 
detrimental to the continuity of patient care.

Perhaps the most conclusive evidence that the implementation of the contract may have detrimentally had an impact on patient care for individuals with complex care needs, was the observed increase in the time taken to start of triage. Unfortunately, data were not available for all patients (any cause) to explore if this pattern was specific to patients with complex needs, or simply reflecting more widespread changes. Although patients with cancer had to wait longer until the start of triage, once the clinical care had commenced there was no change in the length of time taken to resolve the care episode. Difficulties in some providers meeting the national quality requirement response times have recently been highlighted. ${ }^{3}$ This finding is particularly interesting given that Devon Doctors was one of the minority of providers nationally that satisfied this requirement, whereby over $95 \%$ of all calls were triaged within 60 minutes (Avery S, personal communication, 2007).

\section{Strengths and limitations of the study}

This study explored changes in the use of out-ofhours primary care services before and after the implementation of the new contract, for patients with cancer. This group was selected as a proxy for the wider population of patients with complex needs, who may be most at risk under the new arrangements. ${ }^{10}$ Working with a large, not-for-profit provider, the researchers had access to a large, relatively stable population of urban and rural areas composed of socioeconomically diverse communities, although with limited ethnic minority representation.

There are several limitations to this study design. First, the observational design does not allow testing of hypotheses or establishment of causal relationships between the implementation of the new contract and changes in service usage. This issue is common to any study seeking to understand the impact of major policy initiatives on the organisation and delivery of healthcare services, which, by the nature and complexity of the policy implementation, are not readily amenable to more controlled empirical designs. Second, the study restricted its cohort to patients with cancer as at the time of sampling, and the information system (Adastra software) used here (and by more than 95\% of English out-of-hours providers) only recorded case-mix data through text fields, with each call treated separately and no electronic linkage by patient.

\section{Implications for clinical practice}

Due to the observational nature of this study, it is only possible to speculate on the explanations for the complex changes observed. The magnitude of the increased demand (all causes) at follow-up is unlikely to be replicated in subsequent years as the rationalisation of service operating hours is complete. Despite this, the study found evidence that quality of care for patients with cancer had been adversely influenced under the new arrangements.

Out-of-hours providers face substantial, practical difficulties in identifying patients with complex needs, and particularly those with palliative care needs (in part, due to the inherent challenge in documenting when curative treatment finishes and palliative care begins). ${ }^{19}$ It is vital that the software evolves to allow audit and possible targeting and monitoring of vulnerable groups if key goals, such as 'around the clock' effective inter-agency communication ${ }^{10,18}$ embedded within NHS primary care policy and practice, are to be realised. Software has recently been developed to support clinicians by automatically linking the current call to details of previous contacts made by the patient. However, increased use of electronic coding (such as Read codes) by health professionals entering clinical data would simplify the process of identifying patients with specific morbidities.

In-hours primary care services also have an important role. Systems already exist to allow special alerts to be sent to out-of-hours services, providing them with vital information to support patients with complex care packages, ${ }^{20}$ although previous research has identified that they remain under-used. ${ }^{18}$ New incentives outlined in the Quality and Outcomes Framework (2006), ${ }^{19}$ including the identification of patients suitable for inclusion on a palliative care register, ${ }^{21}$ and regular multidisciplinary team meetings to review such patients, provide an ideal mechanism to facilitate greater use of special alerts to out-of-hours services. $^{9}$

\section{Funding body}

This study was funded by Macmillan Cancer Support (Registered Charity Number 261017)

\section{Ethical approval}

The protocol was approved by North and East Devon Local NHS Research Ethics Committee (05/Q2102/24) and the appropriate research governance approval obtained from the eight primary care trusts in Devon

\section{Competing interests}

Sarah Avery is the clinical governance manager for Devon Doctors. There are no other competing interests

\section{Acknowledgements}

We would like to thank the staff of Devon Doctors who supported the field work for this study, and Mrs Sue Blake who assisted in the case ascertainment process.

\section{Discuss this article}

Contribute and read comments about this article on the Discussion Forum: http://www.rcgp.org.uk/bjgp-discuss 


\section{REFERENCES}

1. NHS Confederation, British Medical Association. The new general medical services contract. London: The NHS Confederation, 2003.

2. Thomas K. Out-of-hours palliative care - bridging the gap. Eur J Palliat Med 2000; 7(1): 22-25.

3. National Audit Office. The provision of out-of-hours care in England. Report no: HC 1041. London: The Stationery Office, 2006.

4. Salisbury C. The demand for out-of-hours care from GPs: a review. Fam Pract 2000; 17(4): 340-347.

5. Healthcare Commission. Local health services questionnaire 2003. London:

http://www.healthcarecommission.org.uk/NationalFindings/Surveys/ PatientSurveys/fs/en?CONTENT_ID $=4004644 \&$ chk=V\%2BITtB (accessed 6 Feb 2008)

6. Grol R, Giesen P, van Uden C. After-hours care in the United Kingdom, Denmark, and the Netherlands: new models. Health Aff (Millwood) 2006; 25(6): 1733-1737.

7. Carson D. Raising standards for patients. New standards in out-ofhours care. London: Department of Health, 2000.

8. Department of Health. National quality requirements in the delivery of out-of-hours services. Gateway No. 3776. London: Department of Health, 2004.

9. Murray S, Boyd K, Sheikh A, et al. Developing primary palliative care. $B M J 2004 ;$ 329(7474): 1056-1057.

10. Lakhani M, Fernandes A, Archard G. Urgent care. A position statement from the Royal College of General Practitioners. London: Royal College of General Practitioners, 2007.

11. Worth A, Boyd K, Kendall M, et al. Out-of-hours palliative care: a qualitative study of cancer patients, carers and professionals. $\mathrm{Br} I \mathrm{Gen}$ Pract 2006; 56(522): 6-13.
12. Office of the Deputy Prime Minister. The English indices of deprivation 2004. London: Office of the Deputy Prime Minister 2004.

13. Sackett DL, Richardson WS, Rosenberg W, Haynes R. Evidence-based medicine. How to practice and teach EBM. New York: Churchill Livingstone, 1997.

14. World Health Organization. Cancer pain relief and palliative care Technical Report Series 804. 1990. Geneva ed. Cited on page 21 of Thomas K, (ed). Caring for the dying at home. Abingdon, Oxon: Radcliffe Medical Press, 2003.

15. Kirkwood B, Sterne JAC. Medical statistics: 2nd ed. Oxford: Blackwell Science, 2003.

16. Bland M. An introduction to medical statistics. Oxford: Oxford Medical Press, 1995.

17. Department of Health. The NHS cancer plan. London: The Stationery Office, 2000.

18. Burt J, Barclay S, Marshall N, et al. Continuity within primary care palliative care: an audit of general practice out of hours cooperatives. J Public Health Med 2004; 26(3): 275-276.

19. British Medical Association. Revisions to the GMS contract 2006/2007. http://www.bma.org.uk/ap.nsf/Content/revisionnGMSFeb20062 (accessed 6 Feb 2008)

20. Thomas K. The Gold Standards Framework in community palliative care. Eur J Palliat Care 2003; 10(3): 113-115.

21. Thomas K, Free A, Gold Standards Framework Team. Prognostic indicator guidance to aid identification of adult patients with advanced disease, in the last months/year of life, who are in need of supportive and palliative care.

http://www.goldstandardsframework.nhs.uk/content/gp_contract/Pr ognostic\%20Indicators\%20Guidance\%20Paper\%20v\%2025.pdf (accessed 8 Apr 2008). 